\title{
Inclusion and exclusion criteria used in non-specific low back pain trials: a review of randomised controlled trials published between 2006 and 2012
}

Pål André Amundsen ${ }^{1 *}$ D , David W. Evans ${ }^{1,3}$, Dévan Rajendran ${ }^{1,4}$, Philip Bright $^{4}$, Tom Bjørkli ${ }^{1}$, Sandra Eldridge ${ }^{6}$, Rachelle Buchbinder ${ }^{5}$, Martin Underwood ${ }^{2}$ and Robert Froud ${ }^{1,2}$

\begin{abstract}
Background: Low back pain is a common health complaint resulting in substantial economic burden. Each year, upwards of 20 randomised controlled trials (RCTs) evaluating interventions for non-specific low back pain are published. Use of the term non-specific low back pain has been criticised on the grounds of encouraging heterogeneity and hampering interpretation of findings due to possible heterogeneous causes, challenging metaanalyses. We explored selection criteria used in trials of treatments for nsLBP.

Methods: A systematic review of English-language reports of RCTs in nsLBP population samples, published between 2006 and 2012, identified from MEDLINE, EMBASE, and the Cochrane Library databases, using a mixedmethods approach to analysis. Study inclusion and exclusion criteria were extracted, thematically categorised, and then descriptive statistics were used to summarise the prevalence by emerging category.

Results: We included 168 studies. Two inclusion themes (anatomical area, and symptoms and signs) were identified. Anatomical area was most reported as between costal margins and gluteal folds $(n=8,5 \%)$, while low back pain ( $n=150,89 \%)$ with or without referred leg pain $(n=27,16 \%)$ was the most reported symptom. Exclusion criteria comprised 21 themes. Previous or scheduled surgery $(n=84,50 \%)$, pregnancy $(n=81,48 \%)$, malignancy ( $n=78,46 \%)$, trauma $(n=63,37 \%)$ and psychological conditions $(n=58,34 \%)$ were the most common. Sub-themes of exclusion criteria mostly related to neurological signs and symptoms: nerve root compromise $(n=44,26 \%)$, neurological signs ( $n=34,20 \%)$ or disc herniation $(n=30,18 \%)$. Specific conditions that were most often exclusion criteria were spondylolisthesis ( $n=35,21 \%)$, spinal stenosis $(n=31,18 \%)$ or osteoporosis $(n=27,16 \%)$.

Conclusion: RCTs of interventions for non-specific low back pain have incorporated diverse inclusion and exclusion criteria. Guidance on standardisation of inclusion and exclusion criteria for nsLBP trials will increase clinical homogeneity, facilitating greater interpretation of between-trial comparisons and meta-analyses. We propose a template for reporting inclusion and exclusion criteria.
\end{abstract}

Keywords: Low back pain, Non-specific, Inclusion criteria, Exclusion criteria, Systematic review, Definitions

\footnotetext{
* Correspondence: palandre.amundsen@kristiania.no

${ }^{1}$ Institute of Health Sciences, Kristiania University College, Prinsens Gate 7-9,

0152 Oslo, Norway

Full list of author information is available at the end of the article
}

(c) The Author(s). 2018 Open Access This article is distributed under the terms of the Creative Commons Attribution 4.0 International License (http://creativecommons.org/licenses/by/4.0/), which permits unrestricted use, distribution, and reproduction in any medium, provided you give appropriate credit to the original author(s) and the source, provide a link to the Creative Commons license, and indicate if changes were made. The Creative Commons Public Domain Dedication waiver (http://creativecommons.org/publicdomain/zero/1.0/) applies to the data made available in this article, unless otherwise stated. 


\section{Background}

Low back pain (LBP) is a common and costly problem resulting in a substantial personal, social and economic burden globally $[1,2]$. Low back and neck pain are ranked fourth in terms of disability-adjusted life years, and the leading cause of activity limitation and work absence globally [2-4]. The lifetime prevalence of LBP is between 60 and 84\% [5, 6]. Most episodes of LBP are self-limiting and not related to serious disease [5, 7]. A specific cause of LBP is currently identifiable in only a small minority of people (5-15\%) and includes serious pathology such as malignancy, vertebral fracture, infection or axial spondyloarthritis [7-9]. The term 'non-specific' LBP (nsLBP) is used to refer to instances where no specific cause has been identified [7, 8, 10-13]. The term has no agreed definition despite being used by organisations such as the World Health Organization, International Association for the Study of Pain, Backpain Europe, and the (UK) National Institute for Health and Care Excellence [7, 9, 14-22].

The annual rate of publication for randomised controlled trials (RCTs) that test interventions for people with nsLBP has increased from an average of 5.3 RCTs per year between 1980 and 1999, to 23.3 per year between 2000 and 2012 [23]. Interpretation of the results of these numerous RCTs, requires a good understanding of the study populations that have been included. Similarly, to synthesise the results of RCTs in meta-analyses requires study populations to be reasonably homogeneous across trials. Study populations are determined by the selection or eligibility (inclusion and exclusion) criteria that form the framework for sampling [24]. Little research has examined inclusion and exclusion criteria used in RCTs of LBP populations [24-26]; studies that did, found ambiguous identification of neurological involvement in the selection criteria, and inconsistencies across clinical decision guidelines for LBP. The extent to which trialists have used a consistent approach to identifying people with nsLBP is currently unclear.

As part of a larger study systematically reviewing RCTs of treatment for non-specific LBP, the aims relevant to this paper were to systematically describe the inclusion and exclusion criteria reported in RCTs that test interventions for nsLBP, the frequency of reporting criteria and to classify criteria by theme [23].

\section{Methods}

Research methods in low back pain research have developed over recent decades. To assess current practice in trials, we searched for all trials of nsLBP in MEDLINE, EMBASE, and the Cochrane Register of Controlled Trials, published between January 1, 2006 and January 1, 2012. An example search strategy is included as an additional file [see Additional file 1].
Two of three reviewers (PB, DR or TB), working independently, identified all candidate RCT reports by combining all database hits in an Endnote (Version 14; Thomson Reuters, Philadelphia) library, removing duplicates, and short-listing by title and abstract. Fulltexts were obtained if the titles and abstract alone contained insufficient information for assessment against the criteria (Table 1). Reports that selfidentified as pilot/feasibility studies were excluded as these are by definition not set up to explore effectiveness. Additionally, the inclusion criteria might be different because the aims may be different [27] Further, the inherent problem with low power due to the small sample sizes used, may not be able to be overcome using meta-analytical techniques due to the assumptions about underlying distributions being unrealistic [28].

\section{Data extraction and analysis}

Two of three reviewers (PB, DR or TB) independently extracted data on inclusion and exclusion criteria reported in the methods section of each included trial. One reviewer (PA) entered these data into a database. Following extraction of inclusion and exclusion criteria, we used expert validation of extracted data on $20 \%$ random sample of included trials (95,1\% level of agreement), as has been done in other reviews $[29,30]$.

To identify the categories of reported inclusion and exclusion criteria, we developed a coding framework with themes and subthemes. PA, RF and DR first

Table 1 Inclusion and exclusion criteria and the order of their evaluation

Inclusion criterion

RCTs of nsLBP not failing one of the eight exclusion criteria

Order Exclusion criteria

$1 \quad$ Non-English language reports

2 Studies that were not RCTs or presented insufficient information for us to determine whether randomisation was used to allocate participants

3 Reports that self-identified as pilot/feasibility studies

4 Cross-over designs (because of limited utility in the LBP field)

5 RCTs with mixed samples (e.g. neck or thoracic pain in addition to LBP), samples of participants with radiating leg pain, or referred pain extending past the knee in reports where LBP was not described as non-specific, or samples including LBP specific pathology (e.g. cancer, ankylosing spondylitis, or disc herniation) or pregnancy

6 Trials using solely objective or psychological outcome measures

$7 \quad$ Non-inferiority designs

8 Follow-up studies with no new outcome measures, and multiple publications. In the case of multiple publications, we included the first published article and excluded subsequent publications

$\mathrm{RCT}=$ Randomised controlled trial; $\mathrm{nsLBP}=$ Non-specific low back pain 
familiarised themselves with the extracted data and coded each inclusion and exclusion criterion with labels that described their focus, and then grouped these coded data into clusters of similar interrelated ideas or concepts to form general categories. We used a Microsoft Excel (Microsoft, Washington) spreadsheet to generate a matrix, and the categories were then 'charted' into our framework matrix. We retained the terminology used within RCT reports, aiming to describe the verbatim terms used. However, decisions needed to be made during the process regarding criteria that could be conflated (e.g. spondylolisthesis grade I and spondylolisthesis grade II) to achieve useful data reduction and facilitate interpretation of results. These decisions were made through team discussion and the framework was revised and refined until all the coded data could be modelled within the structure of the framework.

We populated each theme and subtheme of our framework with frequencies of reporting. Frequency distributions were used to summarise the prevalence of reported criterion. All quantitative descriptive analyses were performed using SPSS (IBM, Washington).

\section{Results}

Our initial search identified 6001 studies; we examined full-texts of 311 of these. At full-text level, 143 articles were excluded [50-192], and 168 met the inclusion criteria [193-360] (Fig. 1) [see Additional file 2]. [see Additional file 3: Table S1] shows the characteristics of included studies, and [see Additional file 4: Table S2] shows the characteristics of excluded studies.

\section{Framework of inclusion and exclusion criteria}

Table 2 shows our framework of themes $(n=3)$ and subthemes $(n=27)$ identified from inclusion criteria, while Table 3 shows the identified themes $(n=21)$ and subthemes $(n=117)$ from exclusion criteria.

\section{Inclusion criteria \\ Demographics}

While most studies reported the age, gender and symptom duration of their study population, these demographics were variably included as inclusion criteria. Age was reported as selection criterion in $77 \%$ of the trials. The lower age entry threshold was specified in $74 \%$ of trials and spanned from 15 to 45 years. In contrast, an

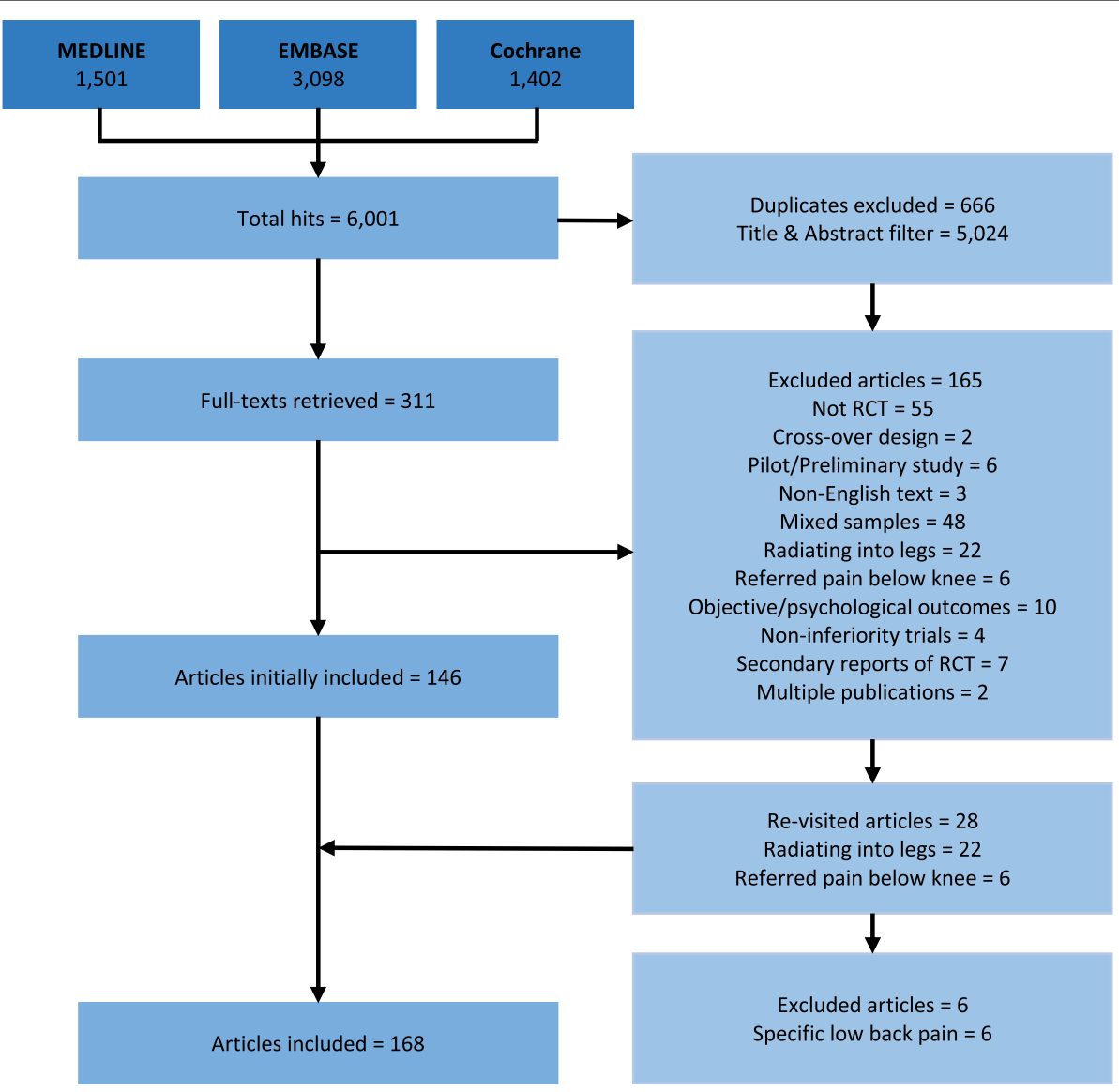

Fig. 1 Flowchart 
Table 2 Inclusion themes and subthemes

\begin{tabular}{|c|c|c|c|}
\hline \multicolumn{2}{|c|}{ Theme } & \multirow{2}{*}{$\begin{array}{l}\text { Subthemes } \\
\text { Between costal margins and gluteal folds }\end{array}$} & \multirow{2}{*}{$\frac{n(\%)}{8(5)}$} \\
\hline 1 & Anatomical area & & \\
\hline & & Below scapulae and above gluteal folds & $3(2)$ \\
\hline & & T6 or below & $2(1)$ \\
\hline & & T7 or below & $2(1)$ \\
\hline & & Low back or buttocks & $2(1)$ \\
\hline & & Between L1 and gluteal folds & $2(1)$ \\
\hline & & Between L1 and SI-joints & $1(1)$ \\
\hline & & At or above waist level & $1(1)$ \\
\hline \multirow[t]{11}{*}{2} & Symptoms and signs & Low back pain & $150(89)$ \\
\hline & & With or without referred Leg pain & $27(16)$ \\
\hline & & Back pain & $10(6)$ \\
\hline & & Without referred leg pain & $7(4)$ \\
\hline & & Pain exacerbated by movement & $5(3)$ \\
\hline & & Limited movement & $3(2)$ \\
\hline & & Stiffness & $2(1)$ \\
\hline & & Tension & $2(1)$ \\
\hline & & With referred leg pain & $1(1)$ \\
\hline & & Pain at rest & $1(1)$ \\
\hline & & Discomfort & $1(1)$ \\
\hline \multirow[t]{23}{*}{3} & \multirow{23}{*}{$\begin{array}{l}\text { Patient-reported outcome measures } \\
\text { with score thresholds for inclusion }\end{array}$} & Visual Analogue Scale* (0 to 100) & \\
\hline & & $\geq 40 \mathrm{~mm}$ & $6(4)$ \\
\hline & & $\geq 30 \mathrm{~mm}$ & $4(2)$ \\
\hline & & $\geq 65 \mathrm{~mm}$ & $1(1)$ \\
\hline & & $\geq 35 \mathrm{~mm}$ & $1(1)$ \\
\hline & & $\geq 20 \mathrm{~mm}$ & $1(1)$ \\
\hline & & $\geq 10 \mathrm{~mm}$ & $1(1)$ \\
\hline & & Oswestry Functional Disability Index (0 to $100 \%$ ) & \\
\hline & & $\geq 30 \%$ & $2(1)$ \\
\hline & & $\geq 25 \%$ & $2(1)$ \\
\hline & & $\geq 20 \%$ & $1(1)$ \\
\hline & & $\geq 15 \%$ & $1(1)$ \\
\hline & & Roland Morris Disability Questionnaire (0 to 24) & \\
\hline & & $\geq 3$ points & $2(1)$ \\
\hline & & $\leq 4$ points & $1(1)$ \\
\hline & & $\leq 5$ points & $1(1)$ \\
\hline & & Numeric Rating Scale (0 to 10 ) & \\
\hline & & $\geq 3$ points & $1(1)$ \\
\hline & & $\geq 2$ points & $1(1)$ \\
\hline & & Von Korff Chronic Pain Grade (0 to 4) & \\
\hline & & $\geq$ Grade 1 & $1(1)$ \\
\hline & & Hanover Ability Questionnaire (0 to 100\%) & \\
\hline & & $\leq 70 \%$ & $1(1)$ \\
\hline
\end{tabular}


Table 2 Inclusion themes and subthemes (Continued)

\begin{tabular}{ll}
\hline Theme & Subthemes \\
\hline & Short-From 36 \\
"moderate pain and moderate disability & (measured by adaptations of items 7 and 8 of SF-36)" \\
Brief Pain Inventory (0 to 10 on Average pain) & "4 points on average pain last 6 months" \\
$1(1)$
\end{tabular}

*Visual Analogue Scale transformed to 0 to $100 \mathrm{~mm}$

upper age entry threshold was specified in $64 \%$ of trials and spanned from 28 to 80 years. Gender was reported as an inclusion criterion in $13(8 \%)$ trials, either as males $(n=3)$, females $(n=2)$ or both $(n=8)$.

While most trial reports $(n=124,74 \%)$ defined duration of back pain as an inclusion criterion, this ranged from one day to 12 months. Figure 2 shows the proportion of trials that used the terms acute $(n=8)$, subacute $(n=9)$ and chronic $(n=54)$, or did not report any term $(n=97)$. The term 'chronic' was used without specifying duration in 8 trials (5\%), while pain of at least 3 months ( $n=27,16 \%$ ) was the most commonly specified duration followed by pain of at least 6 months $(n=9,5 \%)$.

\section{Anatomical area (Table 2, theme one)}

Most trial reports $(n=143,85 \%)$ did not designate a specific anatomical area as an inclusion criterion. For the $21(12 \%)$ that did, the most common specification was 'between the costal margin and above gluteal folds' ( $n=8,5 \%)$, followed by 'below scapulae and above gluteal folds' $(n=3,2 \%)$.

\section{Symptoms and signs (Table 2, theme two)}

While some trial reports were specific when describing pain symptoms (e.g. 'pain at rest') used as inclusion criteria, others defined these more generally (e.g. 'back pain'). Most of the reports described symptoms for inclusion criteria as 'low back pain' ( $n=150$, 90\%), whereas some used 'back pain' even though low back pain was mentioned elsewhere in the paper $(n=10,6 \%)$. Further descriptors, such as 'with or without leg pain' $(n=27,16 \%)$, and 'pain exacerbated by movement' ( $n=$ 5, 3\%), were used. Forty-three reports (26\%) described more than one symptom, whilst three $(2 \%)$ used three or more symptoms as inclusion criteria.

\section{Exclusion criteria}

\section{Conditions (Table 3, themes one to 12)}

Themes one to 12 (i.e. disorders and/or pathologies used as exclusion criteria) and their associated sub-themes could be collectively described as 'conditions'. Specific conditions were the most commonly described exclusion criteria. Most trials $(n=145,86 \%)$ reported at least one condition as an exclusion criterion. The most frequently reported back-related conditions were 'spondylolisthesis' $(n=35,21 \%)$ and 'spinal stenosis' ( $n=31,18 \%)$.

Specified, unspecified or implied systemic or rheumatologic or immunologic conditions were most commonly referred to using terms such as 'inflammatory disease' ( $n=37,22 \%)$, 'osteoporosis' ( $n=27,16 \%)$, and 'rheumatologic disease' ( $n=13,8 \%)$. LBP due to trauma was described as a condition for exclusion in 63 (37\%) trials, most commonly fracture, dislocation and trauma, and major trauma. Psychosocial conditions were exclusion criteria in 58 (34\%) trials, mostly described in umbrella terms, such as 'psychiatric disorder' $(n=35,20 \%)$. Of the excluded conditions related to malignancy, most trials described 'cancer', while some reported 'previous cancer'. Only one trial included 'significant unexpected weight loss', as an exclusion criterion.

\section{Symptoms, signs and other exclusion criteria (Table 3, themes 13 to 19 )}

NsLBP was primarily distinguished by exclusion criteria stating that the back pain was not attributable to a 'specific cause' ( $n=22,13 \%)$, or known 'pathology or disease' ( $n=$ $22,13 \%)$, often being described vaguely. The latter were mostly termed in umbrella or over-arching terms, for example 'red flags indicating serious spinal pathology' ( $n=$ $21,12 \%)$ or 'known or suspected serious pathology' ( $n=$ $10,6 \%)$. Several reports $(n=44,26 \%)$ listed examples of 'pathology or disease' and 'specific cause' and while most of these indicated the same conditions, the terms used varied (e.g. tumours, neoplasm and malignancy).

Symptoms and signs included as exclusion criteria were mostly neurological or inferred neurological conditions. The most prevalent exclusion criteria were 'nerve root compromise' ( $n=44,26 \%$ ), 'neurological signs' ( $n=$ $34,20 \%)$ and 'disc herniation' $(n=30,17 \%)$. The same neurological condition was variably described as 'radicular pain', 'radicular symptoms', 'radiculopathy' and 'sciatica'. Some trial reports $(n=32,19 \%)$ described assessment methods to exclude people with neurological signs and symptoms. These were based on radiographic evidence $(n=16,9 \%)$ and clinical examination $(n=16,9 \%)$; for example, 'positive Straight Leg Raising, and diminished or decreased motor, sensory, and reflex function'. 
Table 3 Exclusion themes and subthemes

\begin{tabular}{|c|c|c|c|}
\hline \multicolumn{2}{|c|}{ Themes } & \multirow{2}{*}{$\begin{array}{l}\text { Subthemes } \\
\text { Spondylolisthesis }\end{array}$} & \multirow{2}{*}{$\frac{\mathrm{n}(\%)}{35(21)}$} \\
\hline 1 & Back-related condition & & \\
\hline & & Spinal stenosis & $31(18)$ \\
\hline & & Spondylolysis & $13(8)$ \\
\hline & & Ankylosing spondylitis ${ }^{\mathrm{a}}$ & $8(5)$ \\
\hline & & Structural deformity & $7(4)$ \\
\hline & & Osteoporotic fracture & $6(4)$ \\
\hline & & Congenital deformation & $6(4)$ \\
\hline & & Disc disease & $3(2)$ \\
\hline & & Sacroiliitis & $3(2)$ \\
\hline & & Severe structural deformity & $3(2)$ \\
\hline & & Scoliosis & $2(1)$ \\
\hline & & Active structural deficit & $2(1)$ \\
\hline & & Severe postural abnormality & $2(1)$ \\
\hline \multirow[t]{14}{*}{2} & \multirow{14}{*}{$\begin{array}{l}\text { Specified, unspecified, implied systemic, } \\
\text { rheumatologic or immunologic conditions }\end{array}$} & Inflammatory disease & $37(22)$ \\
\hline & & Osteoporosis & $27(16)$ \\
\hline & & Rheumatological disease & $13(8)$ \\
\hline & & Rheumatoid arthritis & $12(7)$ \\
\hline & & Fibromyalgia & $9(5)$ \\
\hline & & Autoimmune disease & $4(2)$ \\
\hline & & Reactive arthritis ${ }^{\mathrm{b}}$ & $2(1)$ \\
\hline & & Bone disease & $2(1)$ \\
\hline & & Osteoarthritis & $2(1)$ \\
\hline & & Inflammatory arthritis & $1(1)$ \\
\hline & & Arthritis & $1(1)$ \\
\hline & & Systemic Lupus Erythematosus & $1(1)$ \\
\hline & & Myofascial pain syndrome & $1(1)$ \\
\hline & & Articular impairment & $1(1)$ \\
\hline \multirow[t]{4}{*}{3} & \multirow[t]{4}{*}{ Psychological } & Psychiatric disorders & $35(21)$ \\
\hline & & Depression & $11(6)$ \\
\hline & & Severe psychiatric disorder & $8(5)$ \\
\hline & & Impaired cognition & $7(4)$ \\
\hline \multirow[t]{6}{*}{4} & \multirow[t]{6}{*}{ Other systemic, unspecified } & Systemic disease & $15(9)$ \\
\hline & & Metabolic disease & $10(6)$ \\
\hline & & Visceral disease & $9(5)$ \\
\hline & & Endocrine disorder & $2(1)$ \\
\hline & & Uterine disease & $1(1)$ \\
\hline & & Thyroid dysfunction & $1(1)$ \\
\hline 5 & Trauma & & $63(37)$ \\
\hline 6 & Malignancy & & $78(46)$ \\
\hline \multirow[t]{5}{*}{7} & Infectious & Infection & $42(25)$ \\
\hline & & Infectious spondylopathy & $5(3)$ \\
\hline & & Infectious disease & $4(2)$ \\
\hline & & Previous infection & $1(1)$ \\
\hline & & Abscess & $1(1)$ \\
\hline
\end{tabular}


Table 3 Exclusion themes and subthemes (Continued)

\begin{tabular}{|c|c|c|c|}
\hline \multicolumn{2}{|c|}{ Themes } & \multirow{2}{*}{$\begin{array}{l}\text { Subthemes } \\
\text { Cardiac disease /insufficiency }\end{array}$} & \multirow{2}{*}{$\frac{\mathrm{n}(\%)}{32(19)}$} \\
\hline 8 & Cardiovascular & & \\
\hline & & Vascular disease /insufficiency & $13(8)$ \\
\hline & & Hypertension & $6(4)$ \\
\hline & & Ischemic heart attack & $2(1)$ \\
\hline & & Claudication & $2(1)$ \\
\hline & & Aortic aneurysm & $1(1)$ \\
\hline \multirow[t]{2}{*}{9} & Haematological & Bleeding disorders & $5(3)$ \\
\hline & & Blood coagulation disorder & $2(1)$ \\
\hline 10 & Respiratory & Respiratory disease /insufficiency & $14(8)$ \\
\hline \multirow[t]{8}{*}{11} & Gastrointestinal, liver or renal & Severe renal or hepatic disorder & $5(3)$ \\
\hline & & Liver disease & $2(1)$ \\
\hline & & Gastrointestinal disease & $2(1)$ \\
\hline & & Abdominal hernia & $2(1)$ \\
\hline & & Gastritis & $1(1)$ \\
\hline & & Gastric ulcer & $1(1)$ \\
\hline & & Crohn's disease & $1(1)$ \\
\hline & & Inguinal hernia & $1(1)$ \\
\hline \multirow[t]{5}{*}{12} & Neurological, systemic & Myelopathy & $2(1)$ \\
\hline & & Epilepsy & $2(1)$ \\
\hline & & Seizure disorders & $1(1)$ \\
\hline & & Muscular disease & $1(1)$ \\
\hline & & Muscular dystrophy & $1(1)$ \\
\hline \multirow[t]{6}{*}{13} & General indications of spinal pathology & Pathology or disease "such as" / "e.g" & $22(13)$ \\
\hline & & Specific cause "such as" / "e.g" & $22(13)$ \\
\hline & & Red flags indicating serious spinal pathology & $21(12)$ \\
\hline & & Specific cause identified & $14(8)$ \\
\hline & & Known or suspected serious pathology & $10(6)$ \\
\hline & & Non-mechanical low back pain & $1(1)$ \\
\hline \multirow[t]{16}{*}{14} & Neurological related to the back (symptoms or & Nerve root compromise & $44(26)$ \\
\hline & $\begin{array}{l}\text { Signs or specific conditions referable to involvement } \\
\text { of the spinal cord or nerve roots) }\end{array}$ & Neurological signs & $34(20)$ \\
\hline & & Disc herniation & $30(18)$ \\
\hline & & Sciatica & $17(10)$ \\
\hline & & Radicular symptoms & $16(9)$ \\
\hline & & Signs of nerve root irritation & $15(9)$ \\
\hline & & Cauda equina syndrome & $14(8)$ \\
\hline & & Radiation below knee & $13(8)$ \\
\hline & & Radiculopathy & $10(6)$ \\
\hline & & Progressive neurological signs & $4(2)$ \\
\hline & & Radicular pain & $4(2)$ \\
\hline & & Widespread neurological signs & $3(2)$ \\
\hline & & Leg symptoms & $3(2)$ \\
\hline & & Spondylolisthesis with radiculopathy & $1(1)$ \\
\hline & & Cord compression & $1(1)$ \\
\hline & & Paralysis & $1(1)$ \\
\hline 15 & Previous or scheduled surgery & & $84(50)$ \\
\hline
\end{tabular}


Table 3 Exclusion themes and subthemes (Continued)

\begin{tabular}{|c|c|c|c|}
\hline \multicolumn{2}{|c|}{ Themes } & \multirow{2}{*}{$\begin{array}{l}\text { Subthemes } \\
\text { Pregnancy }\end{array}$} & \multirow{2}{*}{$\frac{n(\%)}{81(48)}$} \\
\hline 16 & Pregnancy-related & & \\
\hline & & Pre-eclampsia & $1(1)$ \\
\hline 17 & Medico-legal issues & & $39(23)$ \\
\hline \multirow[t]{2}{*}{18} & Comorbidities & Comorbidities & $2(1)$ \\
\hline & & Urine or faecal incontinence & $1(1)$ \\
\hline \multirow[t]{12}{*}{19} & Exclusion for feasibility & Not understanding language & $28(17)$ \\
\hline & & Other current treatment & $18(11)$ \\
\hline & & Previous specific treatment & $17(10)$ \\
\hline & & Medication & $13(8)$ \\
\hline & & Contraindications for intervention & $8(5)$ \\
\hline & & Cardiac pacemaker & $6(4)$ \\
\hline & & Current alcohol abuse & $3(2)$ \\
\hline & & Unable to commit to home-exercises & $3(2)$ \\
\hline & & Fever on the day of examination & $3(2)$ \\
\hline & & History of psychosis & $2(1)$ \\
\hline & & History of alcohol abuse & $2(1)$ \\
\hline & & Presence of yellow flags & $1(1)$ \\
\hline \multirow[t]{16}{*}{20} & Miscellaneous & Obesity & \\
\hline & & Body Mass Index $\geq 30$ & $4(2)$ \\
\hline & & Body Mass Index $\geq 40$ & $3(2)$ \\
\hline & & Obesity (not specified) & $2(1)$ \\
\hline & & Body Mass Index $\geq 35$ & $1(1)$ \\
\hline & & Body Mass Index $\geq 28$ & $1(1)$ \\
\hline & & Menstruation & $1(1)$ \\
\hline & & Unable to sit on a stationary bike & $1(1)$ \\
\hline & & Bad balance between trunk flexors and extensors & $1(1)$ \\
\hline & & Inability to walk at least $100 \mathrm{~m}$ without interruption & $1(1)$ \\
\hline & & Neurologic impairment & $1(1)$ \\
\hline & & Behaviour precluding participation in group therapy & $1(1)$ \\
\hline & & Evidence of distress & $1(1)$ \\
\hline & & Patients unable to accurately locate the area of pain & $1(1)$ \\
\hline & & Patient unable to walk without a walking aid & $1(1)$ \\
\hline & & Suspected non-compliance & $1(1)$ \\
\hline \multirow[t]{10}{*}{21} & Patient-reported outcome measures & Visual Analogue Scale (0 to 100) & \\
\hline & 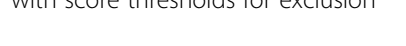 & $\geq 60 \mathrm{~mm}$ & $2(1)$ \\
\hline & & $\geq 80 \mathrm{~mm}$ & $2(1)$ \\
\hline & & Beck Depression Inventory (0 to 63) & \\
\hline & & $\geq 20$ points & $1(1)$ \\
\hline & & $\geq 29$ points & $1(1)$ \\
\hline & & Bothersomeness scale (0 to 10 ) & \\
\hline & & $\leq 3$ points & $1(1)$ \\
\hline & & Numeric Rating Scale (0 to 10 ) & \\
\hline & & $\geq 80$ points & $1(1)$ \\
\hline
\end{tabular}




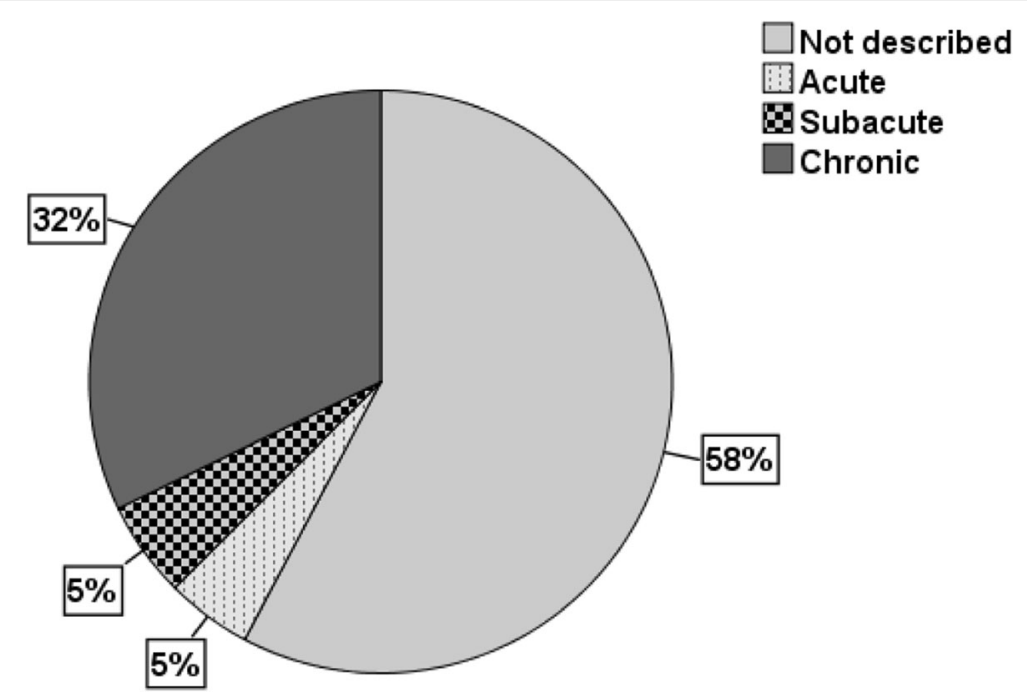

Fig. 2 Pie chart of terms used for duration

Some specific exclusion criteria related to safeguarding the integrity and/or feasibility of the trial. These included exclusion of potential participants who were scheduled for surgery or who had previous surgery related to the back $(n=84,50 \%)$, pregnancy $(n=81,48 \%)$, medicolegal issues $(n=39,23 \%)$, 'not understanding the language' ( $n=28,16 \%)$, 'other current treatment' ( $n=18$, $11 \%)$ or participant's prior experience with a given treatment $(n=17,10 \%)$.

\section{'Miscellaneous' exclusion criteria (Table 3, theme 20)}

A 'miscellaneous' theme included exclusion criteria that were vague, insofar as the meaning or relevance to nsLBP was unclear, rarely reported, or were less easy to categorise. Obesity was reported as an exclusion criterion in 10 trials $(6 \%)$ with a Body Mass Index of 30 or more $(n=4,3 \%)$, or 40 or more $(n=3,2 \%)$ most frequently reported.

Examples of further miscellaneous subthemes include: 'articular impairment,' 'menstruation', 'being unable to sit on a stationary bike, 'bad balance between trunk flexors and extensors', 'neurologic impairment', and individuals with 'evidence of distress'.

\section{Patient-reported outcome measure score thresholds (inclusion theme 3 and exclusion theme 21)}

Thirty-three trials $(20 \%)$ included a patient-reported outcome measure score threshold as a selection criterion. The Visual Analogue Scale (VAS) for pain intensity was most utilised as both an inclusion $(n=14,8 \%)$ and exclusion criterion $(n=4,2 \%)$; the range of VAS score for inclusion was 10 to $65 \mathrm{~mm}$ (mean $34 \mathrm{~mm}$ ) (Table 2), whereas the range of VAS score for exclusion was 60 to $80 \mathrm{~mm}$ (mean $70 \mathrm{~mm}$ ) (Table 3).

\section{Discussion}

Results of this study show that the reported eligibility criteria of people with nsLBP across RCTs is diverse. Trial reports provided relatively fewer details for inclusion criteria than they did for exclusion criteria.

Explicitly reported selection criteria were diverse and only $46 \%$ explicitly reported the exclusion of malignancy. However, exclusion of malignancy in the remaining trials may have been assumed to be implied by the definition of nsLBP. Fewer than half of the trials reported neurological compromise as exclusion criteria, whereas only one quarter of trials reported the inclusion of people 'with or without referred pain'. While most trials reported specific pathologies as exclusion criteria, many of the terms used to describe these were ambiguous or vague, making it difficult to ascertain how these were operationalised. Psychological conditions were reported as exclusion criteria in one-third of trials, which is a surprising finding when the literature proposes that psychological disorders may be a predictor of chronicity in LBP as well as comorbid with pain [31-33]. Use of umbrella or over-arching terms, without specific descriptions of what these were, was frequently seen across all categories of symptoms, signs, and conditions. For example, identification of 'red flags' was used as an exclusion criterion in several trials, despite the vagueness of the term (i.e. 'red flags' can mean different things) and the weak supporting evidence for red flags determining the presence of a specific cause [34].

Our findings demonstrate the heterogeneity of the selection criteria of RCTs purporting to be studying similar populations. The application of these criteria is typically poorly described, creating difficulty for making judgements on the comparability of study populations. 
Explicit reporting of clearly defined inclusion and exclusion criteria, using consistent terminology, would increase our confidence in the clinical homogeneity of nsLBP trial populations, increase the validity of metaanalyses, and improve our ability to interpret and compare the results of individual RCTs and systematic reviews.

RCTs that include or exclude people without clear diagnostic criteria or procedure, could lead to including individuals with different prognoses. Without clear, unambiguous descriptions, the utility of reporting exclusion criteria is limited. For example, intervertebral disc herniation is evident in many asymptomatic individuals, and it may often be the case that participants with asymptomatic herniations are admitted into a trial $[35,36]$.

Of the subthemes of selection criteria that we judged as particularly relevant to back pain, there was inconsistent application between RCTs. For example, spondylolisthesis and spinal stenosis were reported as exclusion criteria in only $20 \%$ of trials, but may have been included under the often-reported general indications of spinal pathology such as "known or suspected pathology' or 'specific cause identified'. Psychosocial conditions were often reported; however, yellow flags were only reported within the selection criteria of one trial [37].

Selection criteria depend on the intervention being tested; there may be good reason for disproportionate focus on biological, psychological or sociological factors. Notwithstanding, over recent decades psychosocial aspects of low back pain have gained much attention [38]. Studies have highlighted the importance of psychosocial factors in the transition from acute to chronic pain; however, we note that few trials used questionnaires designed to assess psychological aspects of pain in relation to the selection of suitable participants for nsLBP trials [38-41].

\section{Comparisons with existing research}

Research on criteria for participating in trials has investigated case definitions and duration of LBP, and specific inclusion and exclusion criteria (e.g. age, though not specifically for nsLBP). These studies show ambiguous presentation of case definitions, duration, and a variation in reported criteria and diagnostic criteria specifically for exclusion of neurological conditions [18, 25, 42]. These results are consistent with our findings. Similar ambiguities have also been described by systematic reviews of trials of interventions for treatment of conditions of the shoulder $[43,44]$ and neck [45].

Our study empirically corroborates the consensus view of the NIH consortium that clinical studies use variable inclusion/exclusion criteria, and supports the NIH Task Force's call to develop and draft research standards for chronic low back pain (cLBP) [24]. We hope that this work will be useful in starting and informing discussion surrounding consensus on appropriate entry criteria and what constitutes sufficient detail to adequately describe cLBP study populations.

\section{Strengths and limitations}

This review utilised a systematic multi-reviewer approach and methods developed a priori to review and categorise the selection criteria in nsLBP RCTs. The review has several limitations, which must be acknowledged. The trials investigated were published between 2006 and 2012; thus, more recently published reports are not represented. Prior to 2006 there were changes in the quality of trial reporting following the introduction of CONSORT [46]. Our view is that there is no reason to expect that any large recent change in entry criteria would materially change our findings. The Task Force Report on Research Standards for Chronic Low-Back Pain was published in 2014 and emphasised the variation in inclusion and exclusion criteria, which may have influenced nsLBP trial investigators to become increasingly aware of describing criteria more homogenously [24].

To identify the selection criteria of included trials, we only searched the methods sections. Therefore, it is possible that additional information about selection criteria could have been reported elsewhere in the paper. We also only included English language papers and it is possible (although unlikely) that our findings may not be generalisable to non-English-language reports. We used an iterative method to describe the selection criteria of included trials and merged some categories together for ease of presentation. While other more complex categorisations could have been used, we don't think is likely to have altered the key findings.

\section{Recommendations for future nsLBP trials and future research}

Following our experience of the challenges of categorising and making a taxonomy of entry criteria domains, we provide in Table 4, for commonly reported domains, examples of the level of detail we suggest is required for the parameters of entry criteria to be sufficiently clear. We offer these suggestions in the spirit of starting and informing discussion surrounding the development of consensus on both clinically relevant domains of entry criteria for LBP trials, and the level of detail required for clarity in the description of how the criterion was operationalised. This approach has worked well previously, where consensus processes have begun with some initial suggestions that are then assessed, scrutinised, and then refined $[47,48]$. We confined ourselves here to making suggestions for only commonly reported domains; although empirical research on what has happened in the past may or may not be the most desirable for informing 
Table 4 Suggested examples for the clear reporting of entry criteria, by commonly reported domains

\begin{tabular}{ll}
\hline Criterion/a & Examples \\
\hline $\begin{array}{l}\text { Anatomical region } \\
\text { If pain below buttock creases is excluded; state any explicit criteria } \\
\text { for exclusions }\end{array}$ & $\begin{array}{l}\text { Pain between bottom of ribs and buttock creases } \\
\text { Pain radiating below knee or objective neurological signs in leg }\end{array}$ \\
$\begin{array}{l}\text { Age } \\
\text { Duration }\end{array}$ & $\begin{array}{l}\text { Adults - with restrictions by age only if good scientific/clinical reason } \\
\text { Back pain problem that has persisted at least } 3 \text { months and has resulted } \\
\text { in pain on at least half the days in the past } 6 \text { months }\end{array}$ \\
$\begin{array}{l}\text { Serious causes of LBP excluded } \\
\text { Rheumatologic conditions excluded }\end{array}$ & $\begin{array}{l}\text { Malignancy, vertebral fracture, infections } \\
\text { Systemic conditions excluded }\end{array}$ \\
$\begin{array}{l}\text { Ankylosing spondylitis or related conditions } \\
\text { Baseline severity for studies of treatment (i.e not prevention) }\end{array}$ & $\begin{array}{l}\text { Cardiovascular, respiratory, neurological, gastrointestinal, urogenital or } \\
\text { related conditions }\end{array}$ \\
NRSNAS $\geq 4 / 40$, or $\geq 15 \%$ of score range of a disability measure \\
(e.g 4/24 for RMDQ) \\
Pregnancy, medico-legal issues, not understanding language, previous or \\
scheduled surgery, psychiatric disorders \\
Study specific criteria
\end{tabular}

Note: The table shows, for commonly reported domains, a series of examples of the level of detail we suggest is required for the parameters of entry criteria to be sufficiently clear

consensus on what should be done in the future. While consistency with what has gone before has value insofar as it facilitates between-trial comparisons, the questions surrounding domain choice and the level of detail that should be provided are principally clinical and in our view, would benefit from separate independent consideration within a Delphi process. [49].

Our paper provides a useful basis for making comparisons with evaluations of nsLBP trials published after 2012 and after the 2014 publication of the NIH report [24]. It will also be important to determine whether there is any improvement in the reporting of selection criteria in future nsLBP trials based upon this paper and our suggested template.

\section{Conclusion}

Inclusion and exclusion criteria in RCTs of nsLBP are diverse, and terms and descriptions used are inconsistent and often described ambiguously using over-arching terms. The use of more consistent selection criteria and unambiguous reporting of these should improve population homogeneity between trials, facilitating comparisons and meta-analyses. We offer a template of criteria as a starting point that may be adapted, if required, depending on the intervention under investigation.

\section{Additional files}

Additional file 1: Typical search strategy. Database search strategy. (DOCX $14 \mathrm{~kb}$ )

Additional file 2: Excluded and included trials. References to excluded and included trials. (DOCX $45 \mathrm{~kb}$ )

Additional file 3: Table S1. Included study characteristics. (PDF $490 \mathrm{~kb}$ ) Additional file 4: Table S2. Excluded study characteristics. (PDF $300 \mathrm{~kb}$ )

\section{Abbreviations}

Cl: Confidence Interval; LBP: Low Back Pain; RCT: Randomised Controlled Trial; YLD: Years Lived with Disability

\section{Acknowledgements}

This project was undertaken as part of the MSc in the Clinical Management of Pain programme, University of Edinburgh. We thank Kristiania University

College, University of Warwick, and Monash University for funding this study.

\section{Funding}

Kristiania University College, University of Warwick, and Monash University. RB is funded by an Australian National Health and Medical Research Council (NHMRC) Senior Principal Research Fellowship.

\section{Availability of data and materials}

The datasets used and/or analysed during the current study are available from the corresponding author on reasonable request.

\section{Authors' contributions \\ $R F, R B, D E, M U, S E, D R, P B$ and TB conceived the PROBE study, upon which this study based. DE, RF, and MU had the initial idea for a systematic review of inclusion and exclusion criteria of nsLBP trials. PA and RF developed the methodology for the study. PA abstracted data from the PROBE database, managed the study, arbitrated reviewers' decisions, performed the analyses, and wrote the first draft of the manuscript. TB, PB, RF and DR performed the data extraction. All authors contributed to the framework formation, commented on the results, discussed the implications, and commented on successive drafts of the manuscript. All authors read and approved the final manuscript. All authors meet the ICMJE guidelines for authorship.}

\section{Ethics approval and consent to participate} Not applicable.

\section{Competing interests}

$P A, T B, P B, D R, D E, R B$, and $S E$ declare that they have no competing interests. $\mathrm{MU}$ is co-author on multiple trials of treatments for nsLBP some of which are included in this review. He has received multiple research grants from NIHR and ARUK as chief or co-investigator, he is an editor for NIHR journal series for which he receives a fee. MU and RF are directors and shareholders of Clinvivo Ltd., a University of Warwick spin-out company.

\section{Publisher's Note}

Springer Nature remains neutral with regard to jurisdictional claims in published maps and institutional affiliations. 


\section{Author details}

${ }^{1}$ Institute of Health Sciences, Kristiania University College, Prinsens Gate 7-9, 0152 Oslo, Norway. ${ }^{2}$ Warwick Clinical Trials Unit. Warwick Medical School, University of Warwick, Gibbet Hill Road, Coventry CV4 7AL, UK. ${ }^{3}$ Centre of Precision Rehabilitation for Spinal Pain, School of Sport, Exercise and Rehabilitation Sciences, University of Birmingham, Edgbaston, Birmingham B15 2TT, UK. ' European School of Osteopathy, The Street, Boxley, Maidstone, Kent ME14 3DZ, UK. ${ }^{5}$ Monash Department of Clinical Epidemiology, Cabrini Institute and Department of Epidemiology and Preventive Medicine, Monash University, Suite 41, Cabrini Medical Centre, 183 Wattletree Road, Malvern, Melbourne, Victoria 3144, Australia. ${ }^{6}$ Centre for Primary Care and Public Health, Queen Mary University of London, 58 Turner Street, Whitechapel, London E1 2AB, UK.

Received: 12 January 2018 Accepted: 4 April 2018 Published online: 12 April 2018

\section{References}

1. Murray CJ, Vos T, Lozano R, Naghavi M, Flaxman AD, Michaud C, et al. Disability-adjusted life years (DALYs) for 291 diseases and injuries in 21 regions, 1990-2010: a systematic analysis for the global burden of disease study 2010. Lancet. 2012;380(9859):2197-223. https://doi.org/10.1016/S01406736(12)61689-4

2. Hoy D, March L, Brooks P, Blyth F, Woolf A, Bain C, et al. The global burden of low back pain: estimates from the global burden of disease 2010 study. Ann Rheum Dis. 2014;73(6):968-74. https://doi.org/10.1136/annrheumdis2013-204428.

3. DALYs GBD, Collaborators H, Murray CJ, Barber RM, Foreman KJ, Abbasoglu Ozgoren A, et al. Global, regional, and national disability-adjusted life years (DALYs) for 306 diseases and injuries and healthy life expectancy (HALE) for 188 countries, 1990-2013: quantifying the epidemiological transition. Lancet. 2015;386(10009):2145-91. https://doi.org/10.1016/S0140-6736(15)61340-X.

4. Lidgren L. The bone and joint decade 2000-2010. Bull World Health Organ 2003;81(9):629.

5. Airaksinen O, Brox JI, Cedraschi C, Hildebrandt J, Klaber-Moffett J, Kovacs F, et al. Chapter 4. European guidelines for the management of chronic nonspecific low back pain. Eur Spine J. 2006;15(Suppl 2):S192-300. https:// doi.org/10.1007/s00586-006-1072-1.

6. Maher C, Underwood M, Buchbinder R. Non-specific low back pain. Lancet. 2017;389(10070):736-47. doi:https://doi.org/10.1016/s0140-6736(16)30970-9.

7. Balague F, Mannion AF, Pellise F, Cedraschi C. Non-specific low back pain. Lancet. 2012;379(9814):482-91. https://doi.org/10.1016/S01406736(11)60610-7.

8. Woolf AD, Pfleger B. Burden of major musculoskeletal conditions. Bull World Health Organ. 2003;81(9):646-56.

9. van Tulder M, Becker A, Bekkering T, Breen A, del Real MT, Hutchinson A, et al. Chapter 3. European guidelines for the management of acute nonspecific low back pain in primary care. Eur Spine J. 2006;15(Suppl 2): S169-91. https://doi.org/10.1007/s00586-006-1071-2.

10. Breivik $H$, Eisenberg $E_{1}$ O'Brien $T$. The individual and societal burden of chronic pain in Europe: the case for strategic prioritisation and action to improve knowledge and availability of appropriate care. BMC Public Health. 2013;13:1229. https://doi.org/10.1186/1471-2458-13-1229.

11. Deyo RA, Weinstein JN. Low back pain. N Engl J Med. 2001;344(5):363-70, https://doi.org/10.1056/NEJM200102013440508.

12. Hollingworth W, Todd CJ, King H, Males T, Dixon AK, Karia KR, et al. Primary care referrals for lumbar spine radiography: diagnostic yield and clinical guidelines. Br J Gen Pract. 2002;52(479):475-80.

13. Frank A. Low back pain. BMJ. 1993;306(6882):901-9.

14. WHO. World Health Organisation 2015. http://www.who.int/medicines/ areas/priority_medicines/BP6_24LBP.pdf?ua=1. Accessed 5 December 2015.

15. Nice.org.uk. The National Institute for Health and Care Excellence 2015. http://www.nice.org.uk/guidance/cg88/chapter/Introduction. Accessed 1 November 2015

16. IASP. International Association for the Study of Pain. http://www.iasp-pain. org/files/Content/ContentFolders/Publications2/ClassificationofChronicPain/ PART_I-C.pdf. Accessed 5 December 2015.

17. Verkerk K, Luijsterburg PA, Heymans MW, Ronchetti I, Pool-Goudzwaard AL, Miedema HS, et al. Prognosis and course of pain in patients with chronic non-specific low back pain: a 1-year follow-up cohort study. Eur J Pain. 2015;19(8):1101-10. https://doi.org/10.1002/ejp.633.
18. de Vet HC, Heymans MW, Dunn KM, Pope DP, van der Beek AJ, Macfarlane GJ, et al. Episodes of low back pain: a proposal for uniform definitions to be used in research. Spine. 2002;27(21):2409-16. https://doi.org/10.1097/01.brs. 0000030307.34002.be.

19. Koes BW, Sanders RJ, Tuut MK. The Dutch Institute for Health Care Improvement (CBO) guideline for the diagnosis and treatment of aspecific acute and chronic low back complaints. Ned Tijdschr Geneeskd. 2004;148(7): 310-4.

20. Krismer M, van Tulder M, Low back pain Group of the B, joint health strategies for Europe P. Strategies for prevention and management of musculoskeletal conditions. Low back pain (non-specific). Best Pract Res Clin Rheumatol 2007;21(1):77-91. doi:https://doi.org/10.1016/j.berh.2006. 08.004.

21. Salath $R, C$, Elfering $A$. A Health- and Resource-oriented perspective on NSLBP. ISRN Pain 2013;2013:19. doi:https://doi.org/10.1155/2013/640690.

22. Dionne CE, Dunn KM, Croft PR, Nachemson AL, Buchbinder R, Walker BF, et al. A consensus approach toward the standardization of back pain definitions for use in prevalence studies. Spine. 2008;33(1):95-103. https:// doi.org/10.1097/BRS.0b013e31815e7f94.

23. Froud R, Patel S, Rajendran D, Bright P, Bjorkli T, Buchbinder R, et al. A systematic review of outcome measures use, analytical approaches, reporting methods, and publication volume by year in low back pain trials published between 1980 and 2012: Respice, adspice, et prospice. PLoS One. 2016;11(10):e0164573. https://doi.org/10.1371/journal.pone.0164573.

24. Deyo RA, Dworkin SF, Amtmann D, Andersson G, Borenstein D, Carragee E, et al. Report of the NIH task force on research standards for chronic low back pain. Pain Med. 2014;15(8):1249-67. https://doi.org/10.1111/pme.12538.

25. Williams C, Hancock MJ, Ferreira M, Ferreira P, Maher CG. A literature review reveals that trials evaluating treatment of non-specific low back pain use inconsistent criteria to identify serious pathologies and nerve root involvement. J Man Manip Ther. 2012;20(2):59-65. https://doi.org/10.1179/ 2042618611Y.0000000025.

26. Haswell K, Gilmour J, Moore B. Clinical decision rules for identification of low back pain patients with neurologic involvement in primary care. Spine. 2008;33(1):68-73. https://doi.org/10.1097/BRS.0b013e31815e3949.

27. Arain M, Campbell MJ, Cooper CL, Lancaster GA. What is a pilot or feasibility study? A review of current practice and editorial policy. BMC Med Res Methodol. 2010;10:67. https://doi.org/10.1186/1471-2288-10-67.

28. Froud R, Rajendran D, Patel S, Bright P, Bjorkli T, Eldridge $S$, et al. The power of low back pain trials: a systematic review of power, sample size, and reporting of sample size calculations over time, in trials published between 1980 and 2012. Spine. 2017:42(11):E680-e6. https://doi.org/10.1097/brs. 0000000000001953

29. Eldridge S. Assessing, understanding, and improving the efficiency of cluster randomised trials in primary care. PhD thesis. Queen Mary University of London: 2005.

30. Froud. R. Improving interpretation of patient-reported outcomes in low back pain trials. PhD thesis.Queen Mary University of London 2010.

31. Nicholas MK, Linton SJ, Watson PJ, Main CJ, Decade of the flags" working G. Early identification and management of psychological risk factors ("yellow flags") in patients with low back pain: a reappraisal. Phys Ther 2011;91(5): 737-753. doi:https://doi.org/10.2522/ptj.20100224.

32. Pincus T, Burton AK, Vogel S, Field AP. A systematic review of psychological factors as predictors of chronicity/disability in prospective cohorts of low back pain. Spine. 2002;27(5):E109-20.

33. Tunks ER, Crook J, Weir R. Epidemiology of chronic pain with psychological comorbidity: prevalence, risk, course, and prognosis. Can J Psychiatry. 2008; 53(4):224-34. https://doi.org/10.1177/070674370805300403.

34. Underwood M, Buchbinder R. Red flags for back pain. BMJ. 2013;347:f7432. https://doi.org/10.1136/bmj.f7432.

35. Savage RA, Whitehouse $\mathrm{GH}$, Roberts $\mathrm{N}$. The relationship between the magnetic resonance imaging appearance of the lumbar spine and low back pain, age and occupation in males. Eur Spine J. 1997;6(2):106-14.

36. Sheehan NJ. Magnetic resonance imaging for low back pain: indications and limitations. Postgrad Med J. 2010;86(1016):374-8. https://doi.org/10. 1136/ard.2009.110973.

37. Diaz Arribas MJ, Ramos Sanchez M, Pardo Hervas P, Lopez Chicharro J, Angulo Carrere T, Ortega Molina P, et al. Effectiveness of the physical therapy Godelive Denys-Struyf method for nonspecific low back pain: primary care randomized control trial. Spine. 2009;34(15):1529-38. https:// doi.org/10.1097/BRS.0b013e3181aa2771. 
38. Nagarajan M, Nair MR. Importance of fear-avoidance behavior in chronic non-specific low back pain. J Back Musculoskelet Rehabil. 2010;23(2):87-95. https://doi.org/10.3233/BMR-2010-0249.

39. Jensen MP. Psychosocial approaches to pain management: an organizational framework. Pain. 2011;152(4):717-25. https://doi.org/10.1016/j. pain.2010.09.002.

40. Pincus T, McCracken LM. Psychological factors and treatment opportunities in low back pain. Best Pract Res Clin Rheumatol. 2013;27(5):625-35. https:// doi.org/10.1016/j.berh.2013.09.010.

41. Vlaeyen JW, Fear-avoidance LSJ. Its consequences in chronic musculoskeletal pain: a state of the art. Pain. 2000;85(3):317-32.

42. Turk DC, Dworkin RH, Allen RR, Bellamy N, Brandenburg N, Carr DB, et al. Core outcome domains for chronic pain clinical trials: IMMPACT recommendations. Pain. 2003;106(3):337-45.

43. Green S, Buchbinder R, Glazier R, Forbes A. Systematic review of randomised controlled trials of interventions for painful shoulder: selection criteria, outcome assessment, and efficacy. BMJ. 1998;316(7128):354.

44. Watts AR, Williams B, Kim SW, Bramwell DC, Krishnan J. Shoulder impingement syndrome: a systematic review of clinical trial participant selection criteria. Shoulder \& elbow. 2017;9(1):31-41. https://doi.org/10.1177/ 1758573216663201.

45. Thoomes EJ, Scholten-Peeters GGM, de Boer AJ, Olsthoorn RA, Verkerk K, Lin $C$, et al. Lack of uniform diagnostic criteria for cervical radiculopathy in conservative intervention studies: a systematic review. Eur Spine J. 2012; 21(8):1459-70. https://doi.org/10.1007/s00586-012-2297-9.

46. Moher D, Hopewell S, Schulz KF, Montori V, Gøtzsche PC, Devereaux PJ, et al. CONSORT 2010 explanation and elaboration: updated guidelines for reporting parallel group randomised trials. BMJ. 2010;340

47. Elbourne DR, Campbell MK. Extending the CONSORT statement to cluster randomized trials: for discussion. Stat Med. 2001;20(3):489-96.

48. Campbell MK, Elbourne DR, Altman DG. CONSORT statement: extension to cluster randomised trials. BMJ. 2004;328(7441):702-8. https://doi.org/10. 1136/bmj.328.7441.702.

49. Froud R, Eldridge S, Kovacs F, Breen A, Bolton J, Dunn K, et al. Reporting outcomes of back pain trials: a modified Delphi study. Eur J Pain. 2011; 15(10):1068-74. https://doi.org/10.1016/j.ejpain.2011.04.015.

Ready to submit your research? Choose BMC and benefit from:

- fast, convenient online submission

- thorough peer review by experienced researchers in your field

- rapid publication on acceptance

- support for research data, including large and complex data types

- gold Open Access which fosters wider collaboration and increased citations

- maximum visibility for your research: over $100 \mathrm{M}$ website views per year

At BMC, research is always in progress.

Learn more biomedcentral.com/submissions 